\title{
Thin Strip Casting of Ni Base Alloys by Twin Roll Process
}

\section{Masao YUKUMOTO and Hiroshi YAMANE}

Iron and Steel Research Laboratories, Steel Development and Production Division, Kawasaki Steel Corporation, Kawasaki-cho, Chuou-ku, Chiba, Chiba-ken, 260 Japan.

(Received on December 26, 1994; accepted in final form on February 17, 1995)

The rapid solidification process, which omits the hot rolling stage in the production of thin strip, was used to produce materials which typically have poor workability. Ni base alloys were cast into a thin strip less than $1 \mathrm{~mm}$ in thickness by the twin roll process. A cast strip was continuously coiled with low tension control and secondary cooling. Coils of these alloys are being delivered as overlay welding hoops after appropriate post treatment.

For quality improvement, various aspects of twin roll casting have been investigated. Melt level control by side-dams and roll profile control have decreased the strip thickness deviation to within $\pm 7 \%$. Internal cavities and localized shrinkage were often detected in strips of these alloys made with flat rolls, while they are rarely detected in the strips produced with grooved roll.

This difference was studied in a two dimensional calculation of solidification. It has been considered that these alloys, if cast with flat rolls, have a longer liquid phase in the strip than the strip cast with grooved rolls, when gas or scale is trapped between the roll and the melt during casting, and that the elongated liquid phase forms internal cavities due to the difficulty of melt flow to the final solidification point.

KEY WORDS: twin roll process; strip quality; thickness deviation; internal cavity; shrinkage; Ni base alloy; over welding hoop.

\section{Introduction}

Since the early 1980's Kawasaki Steel has been developing a twin roll casting process for producing a thin strip less than $1 \mathrm{~mm}$ in thickness. ${ }^{1-8)}$ It is expected that the twin roll caster, when fully developed, will have the following advantages:

(1) Low workability materials will be castable into a thin strip.

(2) A shorter production time will increase delivery efficiency.

(3) A variety of small lot-size products can be manufactured.

These features are advantageous for producing highly alloyed overlay welding hoops such as Ni base alloys and stainless steels..$^{9-11)}$ Moreover, in cast strips of $\mathrm{Ni}$ base alloys, internal cavities and surface cracks are often detected, while they are rarely detected in those of other materials. Recently the twin roll casting technique was developed to the semi-commercial level following to some improvements in strip quality.

This paper describes the newly developed techniques for casting $\mathrm{Ni}$ base alloys and the resulting strip qualities in terms of thickness deviation, surface condition and microstructure. It also discusses the effects of secondary cooling and low tension control for continuous coiling.

\section{Experimental Conditions}

An outline of the 3 ton capacity twin roll caster is shown in Fig. 1. The pouring furnace feeds molten metal in a tundish at a constant flow rate using a sliding nozzle. ${ }^{7,13)}$ The caster consists of a pair of water-cooled rolls and side-dams. The melt is poured from either a slot or a multi-hole type nozzle to the nips of rolls. Figure 2 is a schematic of the side-dam arrangement. ${ }^{14)}$ Sidedams are usually attached to the edges of the rolls to keep the melt flat. The dam plates, made from copper alloy, are cooled at the inner surface by water circulation. The melt gradually solidifies as it makes contact with the copper rolls which kiss each other at a constant rolling force. During casting, the gap between the two rolls is

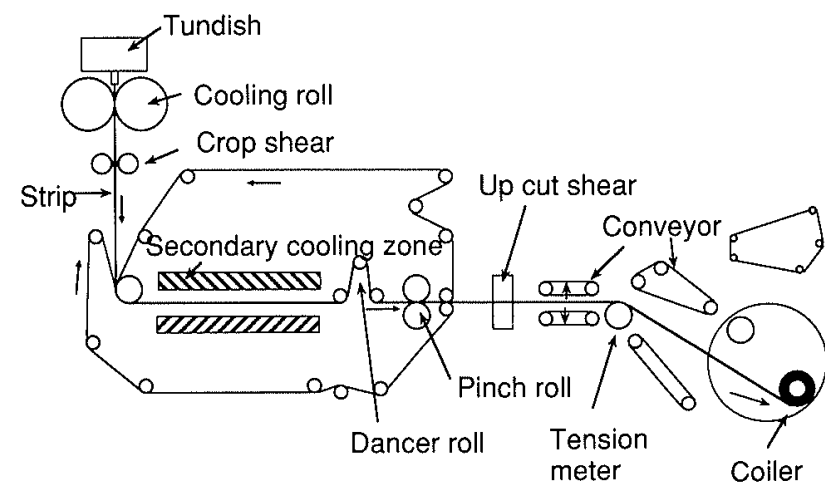

Fig. 1. Schematic drawing of KSC twin roll caster. 


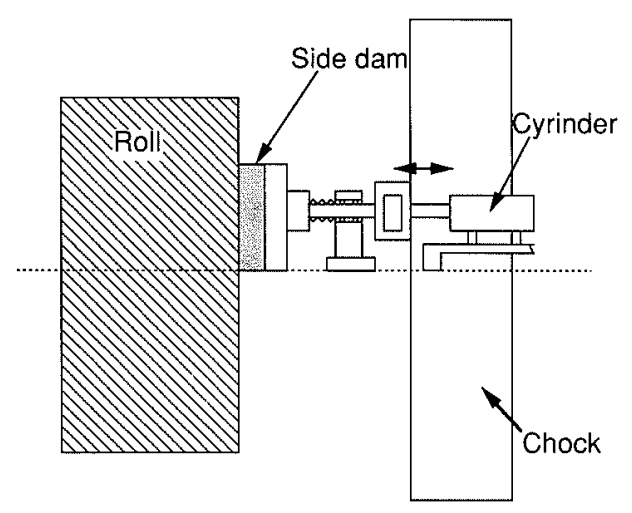

Fig. 2. Apparatus of side dam in twin roll caster.

Table 1. Specification of KSC's twin roll caster.

\begin{tabular}{ll}
\hline Heat size & 3 ton \\
Casting rate & $2-10 \mathrm{~kg} / \mathrm{s}$ \\
Casting speed & $1-7 \mathrm{~m} / \mathrm{s}(60-420 \mathrm{~m} / \mathrm{min})$ \\
Roll diameter & $550 \mathrm{~mm}$ \\
Roll width & $500 \mathrm{~mm}$ \\
Strip thickness & $0.2-0.8 \mathrm{~mm}$ \\
Strip width & $250-500 \mathrm{~mm}$ \\
Coil weight & $500 \mathrm{~kg}$ \\
Cast materials & Inconel alloys (for overlay welding hoop) \\
\hline
\end{tabular}

controlled to a constant value for uniform solidification. ${ }^{1,8,10)}$ The rapidly solidified strip is cooled at a certain rate in the secondary cooling zone by a water jet and then continuously coiled at a constant tension value.

Table 1 shows the specifications of the caster and cast materials. In experiments, the strip thickness ranged from 0.2 to $0.8 \mathrm{~mm}$, and the width was 250 to $500 \mathrm{~mm}$. The rolls are $550 \mathrm{~mm}$ in diameter and $500 \mathrm{~mm}$ in width. The post treatment of cast strips usually includes edgetrimming and descaling.

\section{Results and Discussion}

\subsection{Strip Quality}

\subsubsection{Strip Thickness and Deviation}

Figure 3 shows the appearance of an $\mathrm{Ni}$ base alloy (Inconel 606) coil after edge-trimming and descaling. The strip thickness was within the specification of the Japanese Industrial Standard $(0.4 \mathrm{~mm} \pm 10 \%)$, and the products showed sufficient workability. ${ }^{9}, 10$ )

Three factors have been experimentally identified as the causes of strip thickness deviation: incoming flow rate changes, pool level fluctuations, and roll deformation. ${ }^{10)}$

Figure 4 shows the transverse distribution of strip thickness in Inconel 606. The strip thickness ranged from 0.4 to $0.5 \mathrm{~mm}$. To reduce the transverse changes, sidedams were set on the roll edges and the roll profile was controlled to be flat. When the puddle height was 100 $\mathrm{mm} \pm 4 \mathrm{~mm}$ in casting with side-dams, the strip thickness deviated within $\pm 7 \%$.

\subsubsection{Microstructure}

Typical optical photographs of an as-cast strip of IN606 $(\mathrm{Ni}-8 \mathrm{Fe}-17 \mathrm{Cr})$ and $\mathrm{IN} 600(\mathrm{Ni}-1.5 \mathrm{Fe}-2.5 \mathrm{Nb})$ are shown in Fig. 5. In Fig. 5(a), fine columnar crystals of

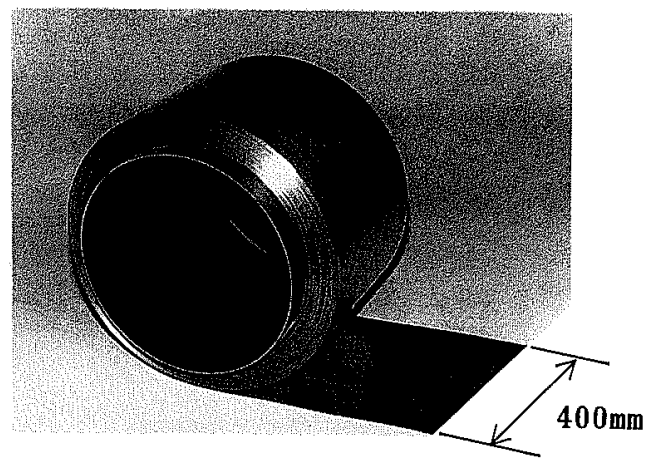

Fig. 3. Strip of IN606 for over-lay welding.

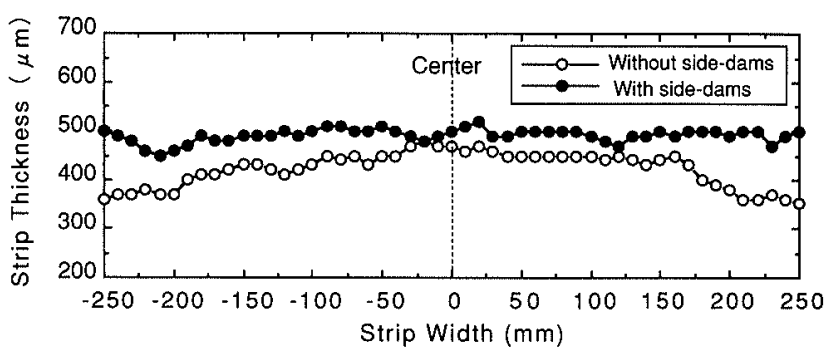

Fig. 4. Transverse distribution of strip thickness in IN606.

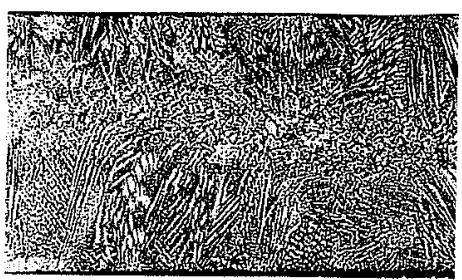

(a)

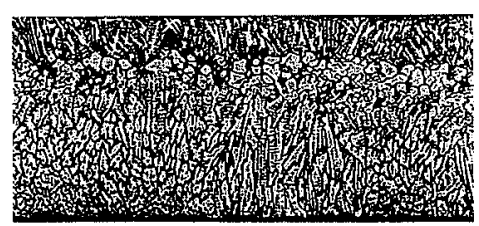

(b)

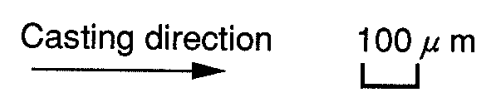

Fig. 5. Optical micrographs of logitudinal section of (a) IN606 and (b) IN600.

dendritic structure developed on both surfaces, and extended almost to the center of the strip. Equiaxed crystals were also observed in the center thickness. By contrast, in Fig. 5(b), coarse crystals of equiaxed structure developed in the thickness direction and grain growth occurred.

The dendrite structure close to the chilled surface was fine and the secondary dendrite spacing (SDAS) varied from 2 to $3.5 \mu \mathrm{m}$, as shown in this figure. The average cooling rate was roughly estimated to be $1-3 \times 10^{3} \mathrm{~K} / \mathrm{s}$ 


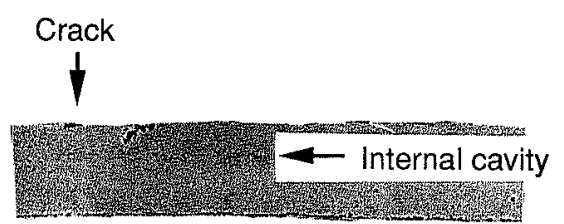

(a) with flat rolls

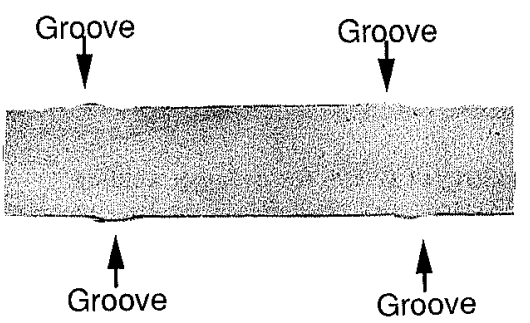

(b) with grooved rolls $0.5 \mathrm{~mm}$

Fig. 6. Transverse cross section of cast strip.

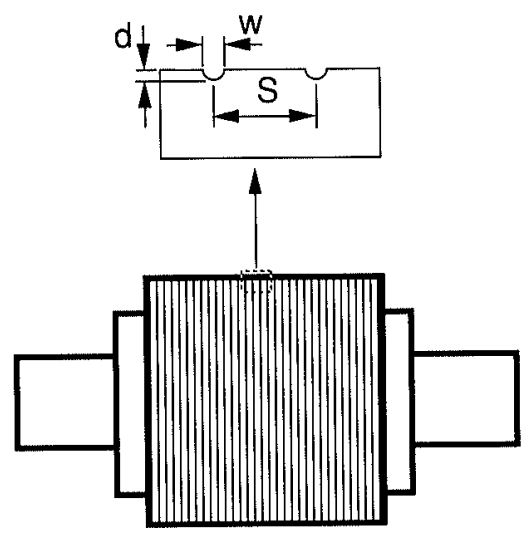

Longitudinal groove

$\begin{array}{|ll|}\text { Groove interval } & s: 1,2 \mathrm{~mm} \\ \text { Groove width } & w: 0.15,0.2 \mathrm{~mm} \\ \text { Groove depth } & d: 0.05,0.1 \mathrm{~mm}\end{array}$

Fig. 7. Schematic view of grooved rolls.

by means of Mehrabian's equation, ${ }^{15)}$ which describes the relation between SDAS and the cooling rate.

\subsubsection{Surface and Internal Defects}

The morphology of surface defects includes surface laps and surface cracks. Roll gap control, ${ }^{1,8)}$ which adjusts the roll axes to be parallel by hydraulic cylinders, is quite effective in preventing these defects.

Internal cavities and localized shrinkage were rarely found in stainless steel, although they were often found in $\mathrm{Ni}$ base alloys having low heat transfer coefficients. Figure 6 compares the transverse section of strips of Inconel 600 cast with flat rolls and grooved rolls. ${ }^{11,12)}$ As shown in Fig. 7, the design of the grooved rolls features longitudinal grooves, $0.2 \mathrm{~mm}$ in width and $0.1 \mathrm{~mm}$ in depth at $2 \mathrm{~mm}$ intervals. It should be noted that in strip cast with flat rolls, internal cavities are often detected at final solidification point, which is near the center of the strip thickness, while they are rarely detected in the strip cast with grooved roll.

Figure $\mathbf{8}$ shows the relationship between the strip

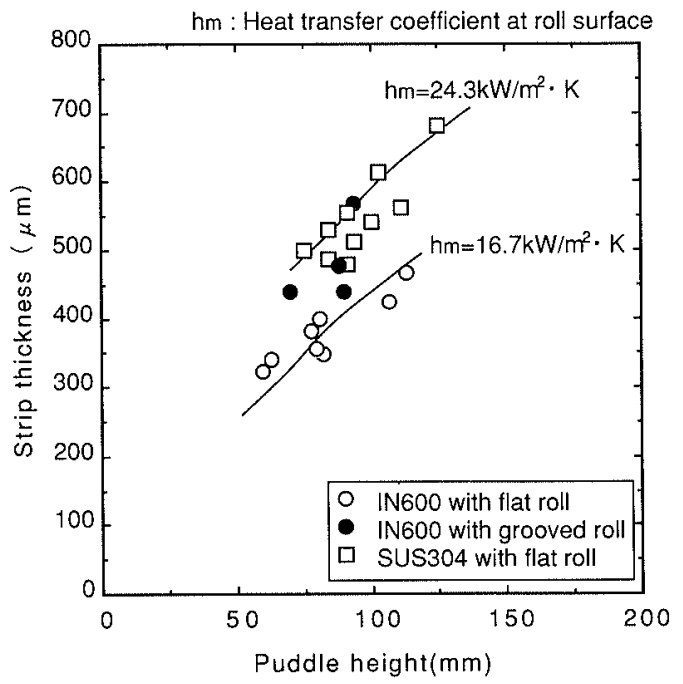

Fig. 8. Relationship between puddle height and strip thickness.

Table 2. Physical properties used in calculations.

$\begin{array}{lll}\text { Liquidus temperature } & 1823 \mathrm{~K} \\ \text { Solidus temperature } & & 1723 \mathrm{~K} \\ \text { Latent heat } & 297 \mathrm{~kJ} / \mathrm{kg} \\ \text { Thermal conductivity } & \text { alloy (steel) } & 29 \mathrm{~W} / \mathrm{m} \mathrm{K} \\ & \text { roll (copper) } & 290 \mathrm{~W} / \mathrm{m} \mathrm{K} \\ \text { Heat transfer coefficient } & \text { alloy and roll } & 16.7,24.3 \mathrm{~kW} / \mathrm{m}^{2} \mathrm{~K}^{*} \\ & \text { roll and water } & 42 \mathrm{~kW} / \mathrm{m}^{2} \mathrm{~K} \\ \text { Roll-sleeve thickness } & & 20 \mathrm{~mm} \\ \text { Casting speed } & & 2 \mathrm{~m} / \mathrm{s} \\ \text { Roll diameter } & 550 \mathrm{~mm}\end{array}$

* Experimentally obtained for Inconel 600 in Fig. 8.

thickness and the puddle height, indicating that when the heat transfer coefficients between the roll and the melt have the values shown in the figure, the results of the one-dimensional calculation ${ }^{2,17)}$ agree well with the experimental data. Accordingly, the average heat transfer coefficient was set at $16.7 \mathrm{~kW} / \mathrm{m}^{2} / \mathrm{K}$ for flat rolls and $24.3 \mathrm{~kW} / \mathrm{m}^{2} / \mathrm{K}$ for grooved rolls when casting Inconel 600 .

The mechanism of cavity formation is considered as follows: Since solidification proceeds slowly in low heat transfer coefficient materials, cast strip of these materials tends to retain unsolidified portions, some of which will leave internal cavities in the strip when solidified afterwards.

\subsection{Modelling and Calculation of Solidification}

The mechanism which causes the shift of the final solidification end point has been mathematically analyzed with a two-dimensional calculation to estimate the degree of the shift. Experimental data on Inconel 600 in Fig. 8 were used in this calculation. The physical properties used in the calculation are listed in Table 2.

The calculation models are schematically shown in Figs. 9 and 10. The temperature and the fraction of solid in the metal were calculated by an explicit finite difference method. ${ }^{16-18)}$ As shown in Fig. 9, it is supposed that gas or scale entrapment takes place at one of these meshes in contact with the roll surface. A lower heat transfer 
coefficient was given to the mesh. The following assumptions were used for calculation.

(1) The metal solidifying between the rolls is divided into small meshes as shown in Fig. 9. The number of meshes contained in one horizontal plane decreases as the plane descends.

(2) If imperfect solidification does not occur, solidification is completed at the kissing point on the rolls. In this case, the fraction of solid is 1.0 .

(3) The temperature recovery method ${ }^{19)}$ is applied

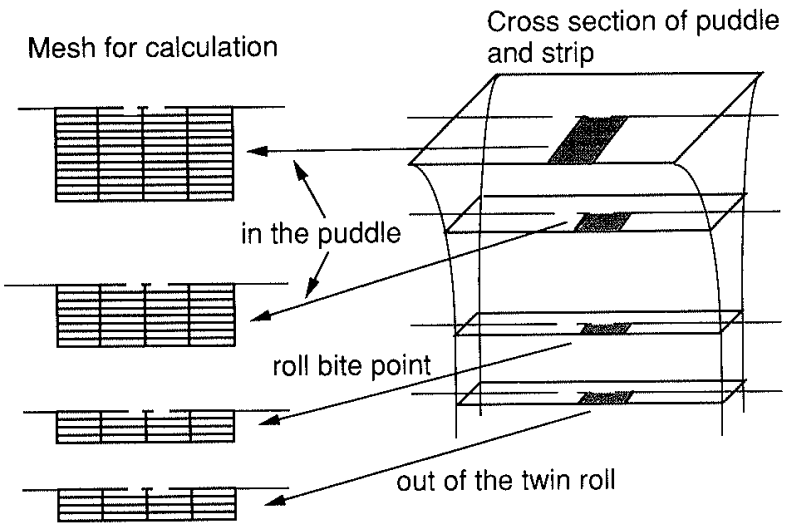

Fig. 9. Model of twin roll casting for two dimensional heat transfer calculation. to obtain the fraction of solid.

(4) The strip is cooled by radiation to the air after it passes the kissing point, as shown in Fig. 10.

Figure 11 shows the fraction of solid obtained by this calculation at several cross sections below the kissing point. It should be noted that in the strip cast with flat rolls, the meshes with a liquid phase extend over a much longer distance than in the strip cast with grooved rolls.

It is schematically shown in Fig. 12. When delayed solidification takes place at such meshes, it is accompanied by volumetric shrinkage. Unless melt is supplied

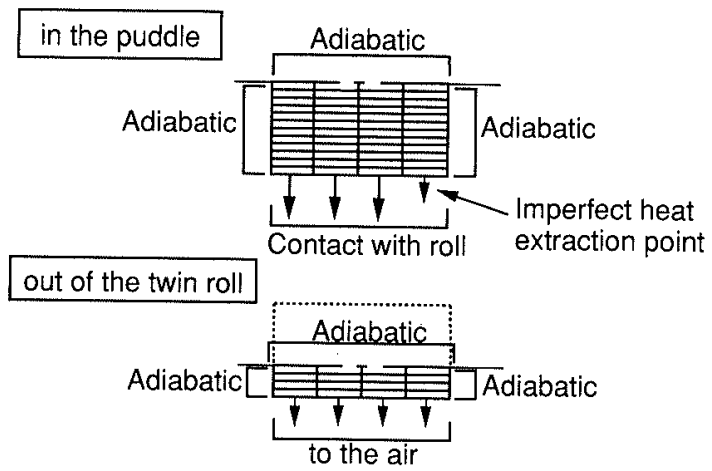

Fig. 10. Condition for two dimensional heat transfer calculation.

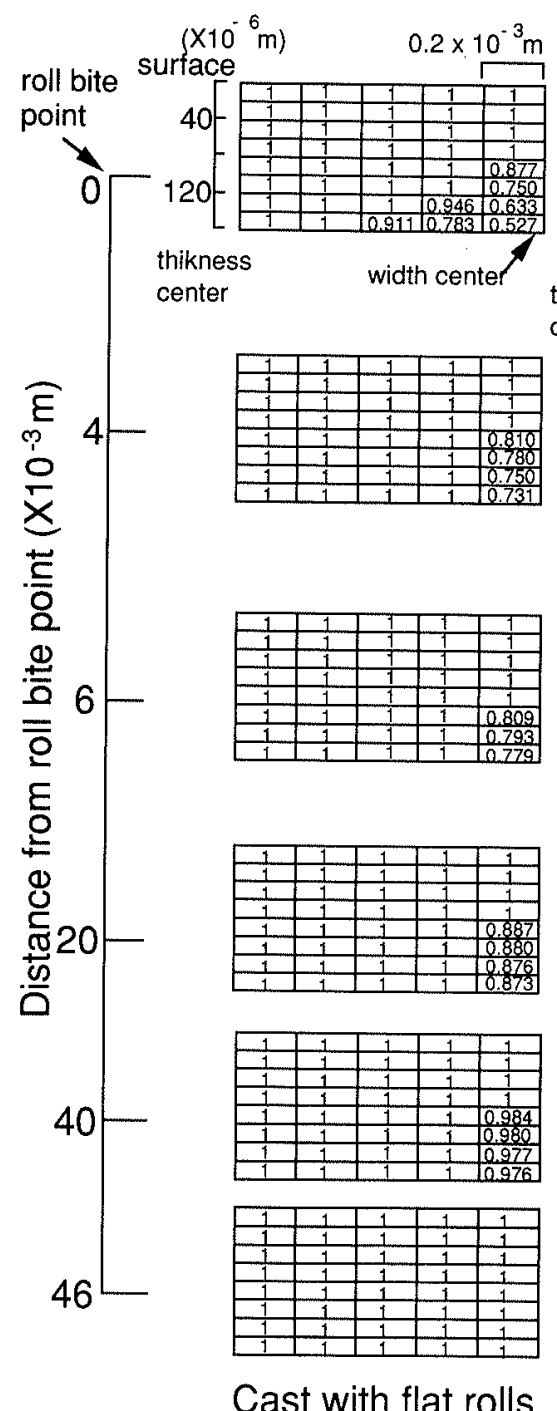

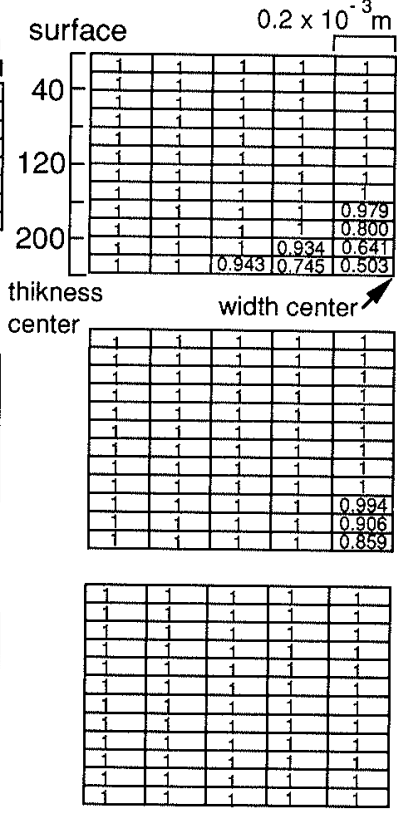

Cast with grooved rolls
Fig. 11.

Change of the fraction of solid in the strip. 
in this region, internal cavities will form. The longer the liquid phase extends below the kissing point, the more difficult it is to fill the shrinkage. Since the strip cast with flat rolls has longer liquid phase than the strip cast with grooved rolls when solidification is imperfect, the strip is more susceptible to the formation of internal cavities.

\subsection{Secondary Cooling}

If a cast strip of high chromium stainless steel and high silicon steel, for example, were continuously coiled without secondary cooling, such advantages as decreased crack formation and refined grain size would be quickly lost due to recrystallization and precipitation. ${ }^{9,20)}$ To pass the precipitation temperature range more rapidly and maintain the tensile strength of the strip, secondary

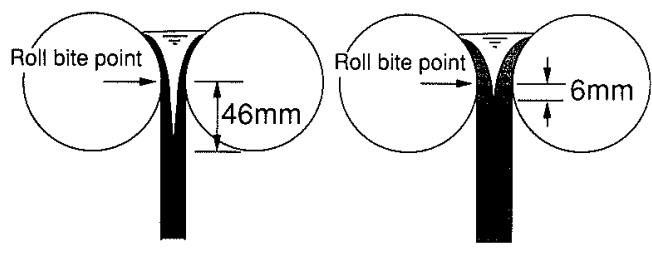

Cast with flat rolls

Cast with grooved rolls

Fig. 12. Extension of liquid phase in imperfect solidification.

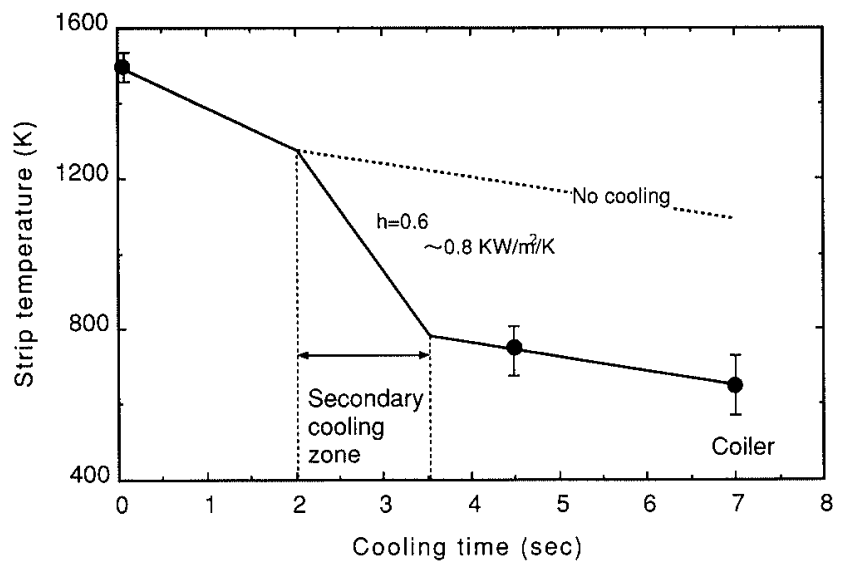

Fig. 13. Changes of strip surface temperature during secondary cooling. cooling was applied in casting $\mathrm{Ni}$ base alloy. In this method, water jets are shot against a travelling strip, as shown in Fig. 1.

The temperature changes of the strip surface, which were measured or calculated during casting, are shown in Fig. 13. The cast strip was as hot as $1500 \mathrm{~K}$ at the outlet of the roll. The strip was cooled in the secondary cooling zone for 1-2s. In this figure, the full circles

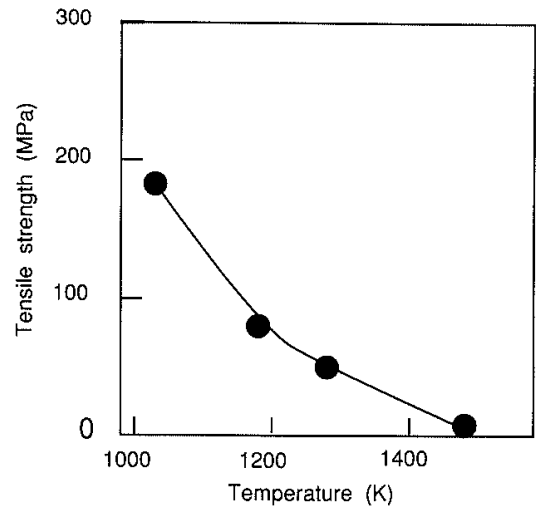

Fig. 14. High temperature strength of IN600.

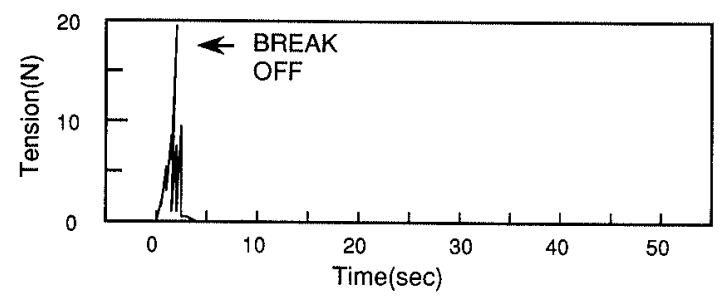

(a) leading the strip to a coiler

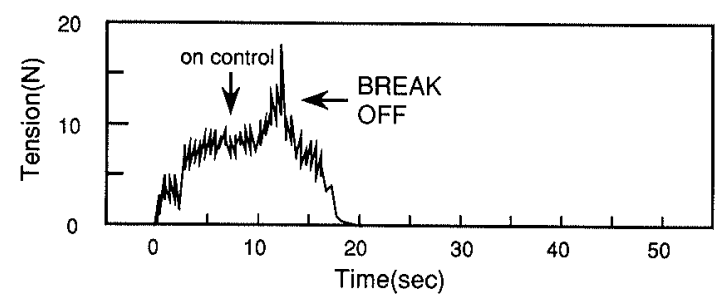

(b) starting to control a tension

Fig. 15. Examples of the strip broken off during a coiling.

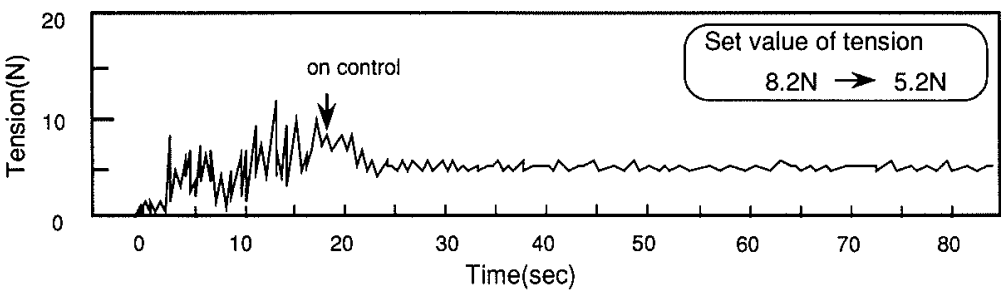

(a) Tension data at pinch roll

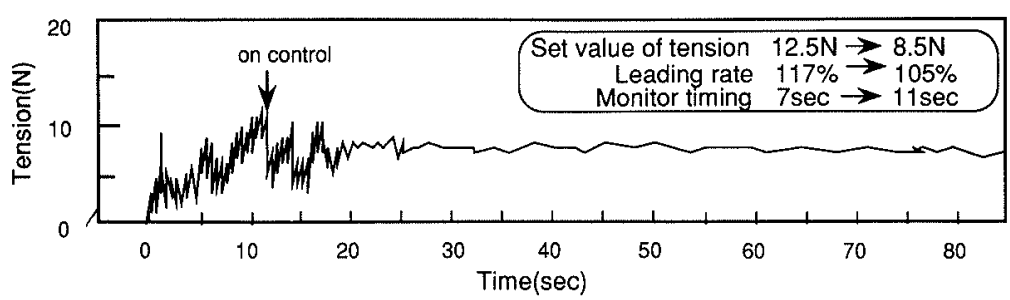

(b) Tension data at coiler
Fig. 16.

Examples of low tension control cast by IN 600 . 
represent the data from a thermometer reading and the line shows the secondary cooling curve of the strip. According to the calculated results, the heat transfer coefficient between the strip and the water was estimated to be $0.6-0.8 \mathrm{~kW} / \mathrm{m}^{2} / \mathrm{K}$ for secondary cooling. The coiling temperature during secondary cooling was kept to below $700 \mathrm{~K}$, and no recrystallization was observed.

\subsection{Low Tension Control for Coiling}

Control of a low tension system was important for the continuous coiling of $\mathrm{Ni}$ base alloys. ${ }^{21)}$

The tensile properties of cast strips as function of temperature for longitudinal direction are plotted in Fig. 14. Since the strips had a large temperature gradient from the outlet of the cooling rolls to the coiler, the strip showed a large strength gradient in this figure.

Figure 15 shows an example of the strip breaked off when casting Inconel 600 . Low tension was required near the outlet of the rolls in order to prevent break-out of the low strength strip. In contrast, high tension was required for tightening coiling to secure a good coil shape. As shown in Fig. 1, these requirements were met by installing pinch rolls and a dancer roll between the cooling rolls and the coiler to divide the tension into two zones. $^{8,9,20)}$

Figure 16 shows an example of low tension control. It is recognized that in $25 \mathrm{sec}$ of casting, the strip tension at the coiler becomes stable at a set value of $8.5 \mathrm{~N}$ when the tension at pinch rolls is $5.2 \mathrm{~N}$. Low tension is adjusted by PID control with a leading rate and monitoring time. $^{21)}$

\section{Summary}

Kawasaki Steel's twin roll caster has been used to cast $\mathrm{Ni}$ base alloys into thin strips of overlay welding hoops. Melt pool level control by side-dams and the roll profile control have decreased the strip thickness deviation to within $\pm 7 \%$.

Casting with grooved rolls has prevents internal cavities and localized shrinkage in Inconel 600. Calculated results showed that the average heat transfer coefficient for grooved rolls is 30\% larger than for flat rolls, and that by casting with grooved rolls, the length of the liquid phase remaining in the strip can be decreased.

Secondary cooling with water jets and low tension control of the coiling system are important for man- ufacturing thin strip of $\mathrm{Ni}$ base alloys. Cast strips of Inconel 606 are being delivered as overlay welding hoops after appropriate post treatments.

\section{REFERENCES}

1) K. Shibuya, T. Kan, Y. Shimizu and Y. Ito: 112th Ann. Meeting of the Metall. Soc., AIME, (1983), Paper A83-15.

2) M. Yukumoto, K. Shibuya, T. Kan and Y. Ito: Rapidly Quenched Metals, Vol. 1, ed. by S. Steeb and H. Warlimont, (1985), 91.

3) F. Kogiku, M. Ozawa, K.Shibuya, H. Shishido and T. Kan: Trans. Iron Steel Inst. Jpn., 26 (1986), 23.

4) F. Kogiku, M. Yukumoto, K. Shibuya, M. Ozawa and T. Kan Mat. Res. Soc. Symp. Proc., 58 (1986), 15.

5) H. Shishido and M. Ishida: Anal. Fis. Serie A, 86 (1990), 117.

6) M. Ozawa, F. Kogiku, M. Yukumoto, S. Miyake and T. Kan: Modeling of Casting and Welding Process 4, ed. by A. F. Giamei and G. J. Abbaschian, TMS-AIME, Warrendale, PA, (1988), 255.

7) S. Miyake, H. Yamane, M. Yukumoto, M. Ozawa and T. Kan: Proc. 1st Japan Int. SAMPE Symp. on New Materials and Processes for the Future, ed. by N. Igata, I. Kimpara, T. Kishi, E. Nakata, A. Okura and T. Uryu, The Nikkan Kogyo Shinbun, Ltd., Tokyo, (1989), 752.

8) K. Shibuya and M. Ozawa: ISIJ Int., 31 (1991), 661.

9) M. Yukumoto, S. Miyake, H. Yamane and M. Ozawa: Rapidly Quenched Metals 7, Elsevier Sequoia, Netherland.; Mater. Sci. Eng., A133 (1991), 842.

10) S. Miyake, H. Yamane, M. Yukumoto and M. Ozawa: ISIJ Int., 31 (1991), 689.

11) M. Yukumoto, H. Yamane and T. Nozaki: CAMP-ISIJ., 7 (1994), 1190

12) H. Yamane, M. Yukumoto, S. Miyake and M. Ozawa: CAMPISIJ., 3 (1990), 1682.

13) S. Miyake, F. Kogiku, M. Yukumoto, M. Ozawa, T. Kan and A. Momoo: Proc. of Int. Symp, on Casting of Near Net Shape Products, ed. by Y. Sahai, J. E. Battles, R. S. Carbonara and C. E. Mobley, TMS-AIME, Warrendale, PA, (1988), 621.

14) M. Yukumoto, H. Yamane and T. Nozaki: CAMP-ISIJ., 6 (1993), 1142.

15) R. Mehrabian: Proc. Int. Conf. on Rapid Solidification Processing, (1977), 9.

16) H. Yamane, M. Yukumoto, S. Miyake and M. Ozawa: $C A M P$ ISIJ., 5 (1992), 1682.

17) H. Yamane, M. Yukumoto, S. Miyake and M. Ozawa: I \& S M, AIME, 10th PTD Conf. Proc., 343.

18) T. Mizoguchi, K. Miyazawa and Y. Ueshima: Tetsu-to-Hagané, 80 (1994), 36.

19) I. Ohnaka and T. Fukusako: Trans. Iron Steel Inst. Jpn., 17 (1997), 410.

20) K. Shibuya, F. Kogiku, M. Yukumoto, S. Miyake, M. Ozawa and T. Kan: Rapidly Quenched Metals 6, ed. by R. S. Cochrane and J. O. Ström-Olsen, Elsevier Sequoia, Netherland,; Mater. Sci. Eng., A133 (1991), 842

2I) M. Yukumoto, H. Yamane and M. Ozawa: CAMP-ISIJ., 6 (1993), 256. 